\title{
Research on the Innovation of the Basic-level Party Construction Work in Colleges under the Visual Field of "Internet+"
}

\author{
Huihua Zhang
}

College of Science and Art, Jingdezhen Ceramic University, Jingdezhen, Jiangxi 333000

\begin{abstract}
With the development of the times, the construction of basic-level party organizations in colleges and universities is also deepening. In the era of "Internet + ", "two micro and one end" new media get a rapid popularization and rooting in colleges, where WeChat" as the representative, based on the flexibility, convenience, uniqueness of new media, "two micro and one end" gradually become a dazzling star in basic-level party building. How to make better use of new media become the current question in basic-level party organizations in our country. Based on this, this paper combined with the current reality of grassroots party building online and outline, analyzing innovation path in colleges party construction, to try to provide a reference for practical work.
\end{abstract}

Keywords: "Internet +"; Basic-Level party building work; Innovation; Online or outline

\section{“互联网+”视域下高校基层党建工作线上线下创 新研究}

张辉华

( 景德镇陶瓷大学科技艺术学院, 江西 景德镇 333000 )

摘要: 随着时代不断变化发展, 高校基层党组织建设工作也在不断深化。“互联网+”时代下, 以微信为代表的“两微一 端” 新媒体在高校快速普及并生根发芽, 基于新媒体的灵活性、便捷性、独特性，“两微一端”逐渐成为基层党建工作中的 一颗耀眼的明星。如何更好得利用新媒体，成为目前我国高校基层党组织思考的问题。正是基于此，本文结合当前高校基层 党建工作线上线下实际, 分析高校党建工作的创新路径, 试图为实际的工作提供参考。

关键词: “互联网+”; 基层党建工作; 创新; 线上线下

中图分类号: TP393.4 文摘标识码: A

引言

伴随着世界信息技术的飞速发展, 以微信为代表的 “两微一端” 新媒体已经逐渐流行于到我国高校青 年大学生群体之中, 并不断改变着我国青年大学生群体的行为模式、交流模式、凝聚模式, 甚至在一定程 度上影响到了当代大学生的人生观、价值观、世界观。因此, “互联网+” 时代如何合理的利用新媒体, 开 创性的开展基层党建工作，是摆在所有高校党务工作者面前的一道难题。

\section{1. “互联网+” 时代对基层党建工作的影响和表现}

\section{1 非正式群体吸引力、影响力考验基层党建工作的前瞻性}

目前我国大多数基层党建工作的思路都是在传统的基层行政组织构架下进行的，带有浓厚的官方色 彩, 正式性、保守性是它的两大特征; 与之形成鲜明对的是, 新媒体所具有非正式性、开放性、互动性等 特征, 这与现代青年大学生崇尚自我、追求人性心理需要遥相呼应, 所以传统青年组织在的号召力、凝聚 力上相对于一些网络非正式群体来讲更弱。如 “我为祖国测空气”、“共享单车志愿者” 等都是通过微博 
等新媒体聚集而发动, 正是网络上这些非正式群里的存在以及快速发展, 对高校传统青年组织诸如学生会、 社团等形成较大的冲击, 为相关活动的开展也带了巨大挑战。

\section{2 互联网信息传播速度之快考验基层党建工作的及时性}

随着 “两微一端”等新媒体的出现，传统媒介如报纸、杂志等无法及时更新的信息，在信息时代变成 了可能和现实, 互联网的飞速发展极大地缩减了信息更新的间隔，信息周转的周期更为快速。过去在传统 媒介下，信息的更新间隔和信息周转的周期允许高校党务工作人员有充足的时间、有思考的余来发现问题 和落实相关工作, 而在 “互联网+” 时代, 由于信息的瞬息万变要求基层党建工作部门必须畅通信息渠道, 建立相应的信息获取、处理、反馈机制, 在迅速、及时了解国家相关方针政策的同时, 还要发挥主观能动 性积极应对失事和错误的信息，让代表着 “正能量”，具有真实、可靠和积极向上的信息，能够迅速传达 到每一位青年学生中。

\section{3 青年学生思想多元化考验工作的创新性}

青年大学生是微信等 “两微一端” 新媒体的忠实 “粉丝”。在目前对新媒体的监督和管理缺乏有效措 施的情形下, 我们每个青年都可能会受各种内容杂乱无章的社会思潮影响生活和学习, 甚至改变价值观, 我们的每个青年学生也都可能成为各种信息的发布者和传导者。目前, 大学校园里活跃的都是 “90 后” 青 年大学生, 由于 “90 后” 大学生基本都是独生子女, 衣食无忧, 心智尚不完全成熟, 大多人都缺乏社会经 验, 明辨是非的能力有限, 在网络信息 “爆炸” 的当下, 他们极易被各种不良思想左右, 产生模糊、错误 的认识和消极、曲解等思想。新媒体下, 青年学生思想的多元化必须加以正确的引导, 共青团干部必须不 断创新工作思维和方法, 做青年学生的 “思想引路人”。

\section{2. “互联网+” 时代下基层党建工作线上线下存的问题分析}

在信息技术的飞速发展，给基层党建工作迎来了全新的机遇和挑战。这新形势下，许多高校的党建工 作也实现了一定的创新与改革, 但是从其最终结果上来说, 还是表现出了几个方面的问题。

\section{1 基层党组织建设工作仍然较为薄弱。}

基层是党组织的稳定基础, 是一切党建工作的基石。时下, 许多高校基层党建工作主要是由相关负责 人负责组织, 一些基层人员往往只是单纯地参与到各项活动之中, 并没有在实际的工作中发挥自身的主观 能动性。这就造成基层党建工作较为薄弱, 没有在基层中形成稳固的党建基础。

\section{2 创新理念缺失, 与时俱进的思维有待提高。}

在长时间的工作中，一些基层工作人员已经形成了固定的思维模式，对相关工作理念固化，创新理念 严重不足, 与时俱进的能力有待提高。在 “互联网+” 视域下展开基层党建, 部分党务工作者对创新工作 很难形成有效的认识, 在实际的过程由于对互联网的认识不够深入导致其更无法在工作中提出切实可行的 意见和建议, 这就使得基层党建工作在 “互联网+” 背景下无法实现快速创新, 依旧维持在传统的工作老 路上, 造成其工作效率和工作成效低下。

\section{3 工作方法和措施单一, 创新原动力不足。}

创新党建工作需要多措并举, 对其形成全面的支撑, 尤其是在互联网飞速发展的今天, 如何有效的利 用线上和线下成为推动工作发展进步的重要路径。尤其是在互联网 + 视域下, 要实现中华民族伟大复兴的 中国梦需要多方共同努力, 这和基层党建创新需要多措并举是不谋而合的。因此, 鉴于当前实际情况, 方 
法和措施单一的问题一定程度上影响了了基层党建工作的创新。

\section{3. “互联网+”视域下基层党建工作的新思路和新路径}

“互联网+”时代下, 党建工作要想在引领青年大学生成长, 就药不断创新工作思路、更新工作方法, 在不断接受新生事物的同时, 充分利用互联网时代下的新技术开展基层党建工作, 因此基层党建工作要在 “线上” 和 “线下”、“在线” 和 “离线” 两个大平台上做好功夫。

\section{1 在基层党建工作中融入新媒体的理念、合理使用 “两微一端”}

党建工作部门是高校青年思想引领的重要部门, 其工作思路的能否与时俱进直接决定着基层党建工作 的成效。时代在发展, 技术在进步, 这也不断促使基层党务工作者们要利用时下的网络新媒体来不断创新 基层党建工作。基层党建工作部门和党务工作者都要不断学习现代互联网新技术, 在互联网飞速发展的时 代就应该在实际工作中合理融入微信等新媒体的工作理念, 使青年大学生群体对 “两微一端” 等具有代表 性的新媒体有正确、客观的认识和应用，并积极引导各级基层组织、基层工作人员合理正确使用新媒体, 在实际工作中充分发挥新媒体这一网络载体在基层党建工作中的作用。

\section{2 充分发挥新媒体作用, 着力打造 “线上” 基层党建工作新平台}

1、拓宽 “线上”工作平台。随着网络、手机 APP 技术的迅速发展及广泛应用, 新媒体在青年大学生 得到了广泛的应用, 这为基层党建工作的创新开展提供了广阔空间。因此, 基党建工作部门可以根据自身 具体工作实际, 着力打造党建工作 “网上” 平台。通过此类新媒体发布党建工作信息, 也能及时把握青年 大学生的生活现状和思想动态, 实现信息的双向互通。此外, 还可以组织内部建立诸如微信群、飞信群等 交流平台, 改变以往的单线点对点联系向多线多项面对面的实时互动联系, 实现资源共享和信息互通, 提 高基层党建工作的凝聚力和向心力。

2、开辟基层党建工作 “在线”工作阵地。新媒体时代所突出展现的信息技术变革是通过互联网最直 观地表现出来的。因此在必须重视网络载体在实际工作的应用, 建立网上党支部、开通党员教育微博、微 信群平台、微信公众平台等。在重视 “面对面” 传统组织生活模式的过程中, 不断创新 “键对键” 新媒体 时代的青年生活新模式。基于此, 基层党建工作部门要充分利用青年大学生对追求网络的便捷、快速生活 的内在需求的时候, 开辟网路党建工作阵地, 开展丰富多彩的网络主题活动, 利用网络形象、生动、直观 的特点, 提高基层党建工作活动的趣味性。

\section{3 以新媒体为依托, 构建基层党建工作学习型党组织}

《中共中央关于加强和改进新形势下党的建设若干重大问题的决定》, 提出把建设马克思主义学习型。 这是基层党组织加强自身建设的客观需要。基层党建工作要立足于新媒体大环境, 以微媒体为依托, 在 “线 上” “线下” 不断积极拓展基层党组织、青年大学生学习的内容、途径、方式, 不断创新学习型党组织建 设的思路和工作机制。在实际工作中开展诸如 “集中学习周”、学习研讨、交流、讲坛等, 以及党员青年 自觉学等活动, 提升基层党建工作的理论水平和高度。

\section{4 以第二课堂为基点, 建立党校微课堂, 推进青年马克思主义者培养工程}

在青年马克思主义者培养工程课堂上不断改革教学方法、更新教学内容、夯实教学目标, 并不同层面 做的深入的探讨和梳理。从改革教学内容上, 要在坚持传统教学内容的过程中不断引入新思维、新思路、 新方法, 在实际教学过程中, 都要自觉增加诸如防腐拒变这类与时下内容紧密相关的内容, 让广大青年大 
学生在比较中鉴别、在鉴别中接受并潜移默化; 从教学方法上, 一方面需要授课老师有广博的知识和超强 的分析引领能力, 也用不断学习网络新媒体知识, 让教学方法更接地气。另一方面要不断引入新媒体加入 到教学的过程中, 比如充分发挥微博的转发功能、微信的推送功能、微公益的互动公益功能等; 在夯实教 学目标上, 则不仅要强调提高广大青年大学生的学习和实践能力。

\section{5 重视 “线下” 项目, 主动贴近广大青年学生}

在深刻理解新媒体环境下青年学生的思想特点同时, 需要进一步了解他们对新媒体环境的极大融入 性, 从青年大学生的兴趣点以及实际情况出发, 结合青年大学生开阔和崇尚创新的个性特征, 在 “线下” 开展一系列能够体现, 该时代青年特点, 能展现他们风采的活动, 在实际过程中教育、帮助和引导他们在 积极享用新媒体带来的便利和便捷的同时, 不沉迷于网络, 开展诸如 “走下网络、走出宿舍、走向操场” 类型的三走活动, 积极吸引凝聚广大青年, 让他们充分参与到校园文化活动中, 积极向党组织向优秀看齐; 另一方面, 要全面分析新媒体环境的复杂性, 在实际过程中提高基层党建工作在思想政治工作的针对性, 尤其是广大党务工作者要放下身价, 深入到青年中, 与他们一起参加活动, 一起体味成长, 确实做到贴近 青年。

\section{4.结语}

随着世界范围内经济社会的不断发展变化, 信息网络化已经成为我们日常生活中非常重要的工作方 法。面对信息技术飞速发展的今天, 作为青年大学生思想引领的基层党组织, 无论是从组织还是党务工作 者自身都应该有时代的紧迫感和强烈的忧患意识, 在实际工作中要不断创新思维, 转变工作方式、方法, 提高个人学习能力和业务水平, 利用现代网络技术创造性的开展党建工作, 努力开拓出基层党建工作的新 局面。

\section{致谢}

基金项目：2016 年度江西省高校党建课题: “互联网+”视域下高校基层党组织建设工作线上线下创新 研究 (16DJQN034)

\section{Acknowledgement}

Fund Project: 2016 Jiangxi Provincial Party Building Project: Research on the Innovation of the basic-level party construction work in colleges under the visual field of "Internet+" (16DJQN034)

\section{参考文献}

[1] 互联网+党建: 新时期高职党建工作的创新探索与实践, 贾敏; 郑伟光, 中国市场, 2016-11-18

[2] “互联网+” 基层党建探析, 刘毅, 领导科学, 2016-12-10

作者简介:

张辉华, 男, 硕士, 景德镇陶瓷大学科技艺术学院讲师, 研究方向为高校学生工作、高校党建工作

\section{References}

[1] Internet + party building: the new era of higher vocational party building innovation exploration and practice, Jia Min; Zheng Weiguang, Chinese market, 2016-11-18

[2] "Internet +" baisc-level party building analysis, Liu Yi, Leading Science, 2016-12-10 